Globus Journal of Progressive Education A Refereed Research Journal

Vol 10 / No 1 / Jan-Jun 2020

ISSN: 2231-1335

\title{
TEACHING AND MOTHER TONGUE PROFICIENCY OF PRE - SERVICE TEACHERS: HOW COMPETENT
}

"Vanessa Joy Z. Judith

\begin{abstract}
This study determined the Teaching Competence and the Mother Tongue Proficiency of the Pre Service Teachers of the Bachelor of Elementary Education students major in General Education, Home Economics and Livelihood Education and Early Childhood Education respectively in Carlos Hilado Memorial State College for Academic Year 2016 -2017 when taken as a whole and grouped according to major and sex and the significant difference and relationship between teaching competence and mother tongue proficiency. The descriptive method of research was used in this study. Stratified random sampling was employed in the selection of participants. There were ninety seven (97) participants in this study. Mean, Standard Deviation, ANOVA and Pearson $r$ were used to analyze the data. The data for the teaching competence were taken from the Teaching Evaluation and Rating Sheet and Mother Tongue Proficiency was based on the grades by the respondents in their EDMOTO (Mother Tongue) subject. The study revealed that: (1)teaching competence of the pre-service teachers when taken as a whole and grouped according to major and sex was "very high", (2) the mother proficiency of the pre-service teachers was when taken as a whole and grouped according to major and sex was "good", (3) significant difference and significant relationship exists between teaching competence and mother proficiency.
\end{abstract}

Keywords: Teaching Competence, Mother Tongue Proficiency, Pre- Service Teachers.

\section{Introduction}

The term "competencies" is increasingly being used in education circles today. It is a description of one's ability, a measure of one's performance. A person's competencies may be defined in terms of one's knowledge, skills and behaviors. These competencies are require of a teacher specifically because their task is closely tied to the nature of the classroom. Today's classrooms call for teachers to "prepare virtually all students for higher order thinking and performance skills once reserved to only a few" (Darling-Hammond, 2006). Researchers and practitioners are becoming increasingly aware that the character of the $21 \mathrm{st}$ century classroom - and thus the demands on both students and teachers - is undergoing significant change. In the $21^{\text {st }}$ century classroom the roles of the teachers that were identified included: nurturing the whole child, providing quality learning, working with others and developing a strong set of personal values.

In the Philippines, one of the recent changes in Basic Education Curriculum brought by the new K12 program is the introduction of Mother TongueBased Multilingual Education (MTB-MLE) specifically in Kindergarden, Grades 1, 2 and 3 to support the goal of "Every Child-A-Reader and AWriter" by Grade 1." Mother Tongue is used as a Medium of Instruction (MOI) for Grades 1, 2 and 3in teaching Math, Araling Panlipunan (AP), Music, Arts, Physical Education and Health (MAPEH) and Edukasyon sa Pag- uugali (EsP). Mother tongue is taught as a separate Learning Area in Grades 1 and 2, and since the implementation of this three - year old language policy.

The success of mother tongue- based multilingual education (MTB MLE) programs- indeed, of all education- depends in large part on the teacher in the classroom. Teachers must learn how to present curriculum materials in a way that allows children who understand and speak the school language to gain the prescribed standards for their grade level. They must be proficient also in using the language for instruction, (Malone, et. al, 2011).

It is in this light that the researcher necessitated to conduct a study on the Mother Tongue Proficiency and Teaching Competence of the Pre - Service Teachers of the Bachelor of Elementary Education Program in Carlos Hilado Memorial State College for Academic Year 2016 -2017. 


\section{Statement of the Problem}

The purpose of the study is to determine the Mother Tongue Proficiency and Teaching Competence of the Pre - Service Teachers of the Bachelor of Elementary Education Program in Carlos Hilado Memorial State College for Academic Year 2016 -2017.

Specifically, it seeks to answer the following:

1. What is the level of teaching competence of the Pre- Service Teachers in terms of lesson plan preparation, lesson presentation, classroom management, evaluation of student's performance and communication skills and personal attribute when taken as a whole and grouped according to major and sex?

2. What is the level of Mother Tongue Proficiency of the Pre- Service Teachers when taken as a whole and grouped according to major and sex?

3. Is there a significant difference between mother proficiency and teaching competence?

4. Is there a significant relationship between mother tongue proficiency and teaching competence?

5. Based on the result of the study, what enhanced program should be formulated?

\section{Conceptual Framework}

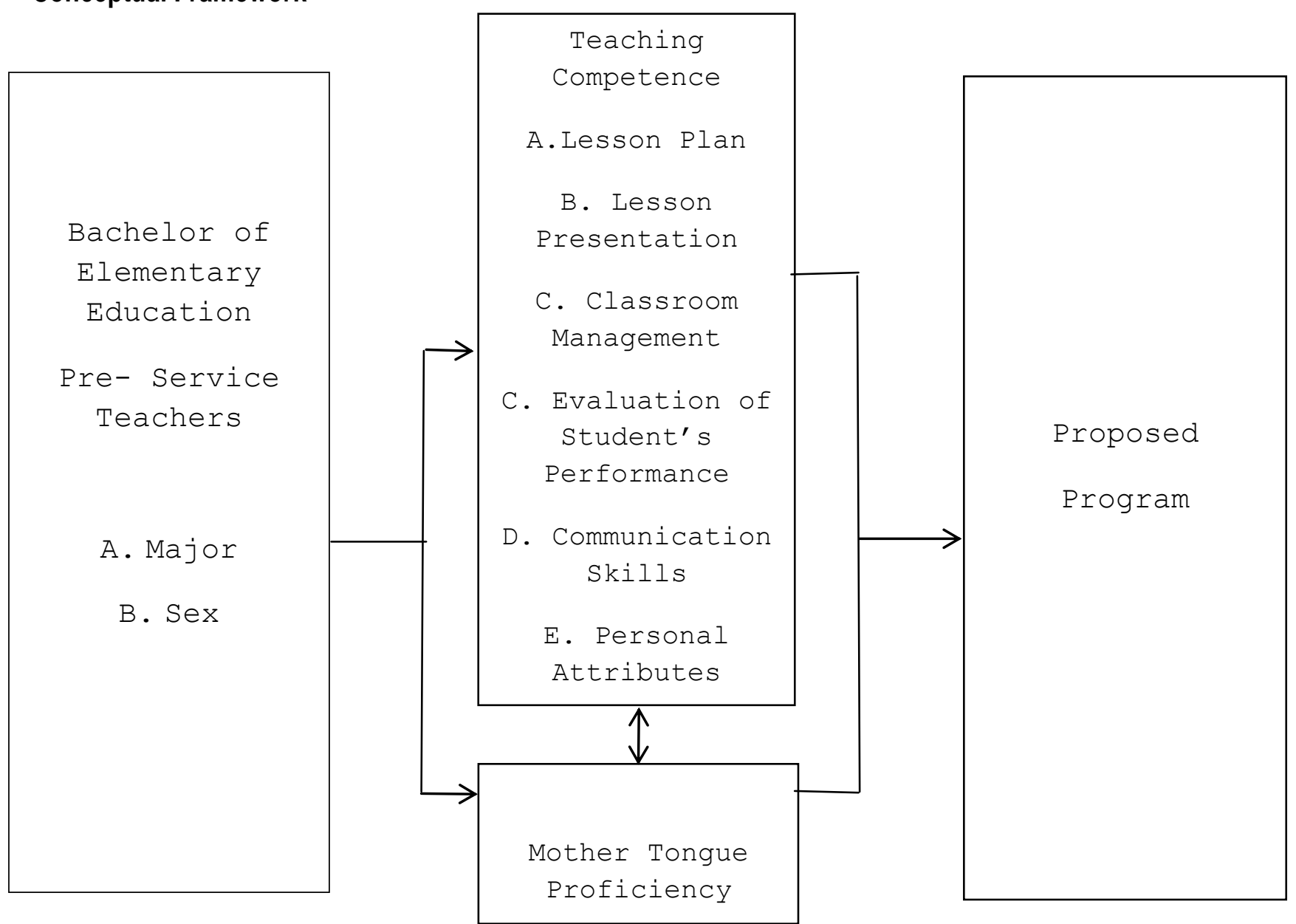

\section{Scope and the Limitation of the Study}

This study was limited itself in determining the teaching competence and the Mother Tongue Proficiency of the Pre- service teachers in Bachelor of Elementary Education in Carlos Hilado Memorial State College- Talisay Campus for AY 2016-2017.

\section{Method of Research Used}

The descriptive method of research was used in this study.

Stratified random sampling was employed in the selection of the participants. 


\section{Respondents of the Study}

The participants of this study were the Pre- Service teachers in the Bachelor of Elementary Education for Academic Year 2016- 2017.

\section{Research Instrument Used}

The Rating and Evaluation Sheet used in the evaluation and monitoring of the Pre-service teachers in the College of Education was used to determine the teaching competence of the participants and the Grades in EDMOTO (Mother
Subject) was used to determine the level of Mother proficiency of the participants.

The statistical tools that were used to determine the reliability and the interval consistency of the instrument was the alpha coefficient known as Cronbach Alpha.

The means and standard deviation were employed as descriptive statistics while $\mathrm{t}$ - test for the independent samples, One- Way Analysis of Variance and Pearson Product Moment Coefficient of correlations were used as inferential statistics.

\section{Results and Discussion}

\section{Table 1}

\section{Teaching Competence of the Pre-Service Teachers when grouped according Major}

\begin{tabular}{llll}
\hline Variables & M & SD & Interpretation \\
\hline A. As a Whole & 4.90 & 0.080 & Very High \\
B. Lesson Plan & & & \\
Gen Ed & 4.99 & 0.041 & Very High \\
HELE & 4.83 & 0.314 & Very High \\
ECE & 4.93 & 0.131 & Very High \\
C. Presentation of the Lesson & & & \\
Gen Ed & 4.82 & 0.185 & Very High \\
HELE & 4.80 & 0.245 & Very High \\
ECE & 4.93 & 0.131 & Very High \\
D. Classroom Management & & & \\
Gen Ed & 4.84 & 0.197 & Very High \\
HELE & 4.72 & 0.191 & Very High \\
ECE & 4.90 & 0.138 & Very High \\
E. Evaluation of Students Performance & & & \\
Gen Ed & 4.99 & 0.041 & Very High \\
HELE & 4.96 & 0.116 & Very High \\
ECE & 4.99 & 0.086 & Very High \\
F. Communication Skills & & & \\
Gen Ed & 4.70 & 0.463 & Very High \\
HELE & 4.81 & 0.402 & Very High \\
ECE & 4.79 & 0.410 & Very High \\
G. Personal Attributes & & & \\
Gen Ed & 4.97 & 0.164 & Very High \\
HELE & 4.97 & 0.090 & Very High \\
ECE & 4.95 & 0.186 & Very High \\
\hline
\end{tabular}

Legend:

\begin{tabular}{ll} 
Scale & \multicolumn{1}{r}{ Interpretation } \\
4.21 to $5.00-$ & Very High \\
3.41 to $4.20-$ & High \\
2.61 to $3.40-$ & Average \\
1.81 to $2.60-$ & Low \\
1.00 to $1.80-$ & Very Low
\end{tabular}

Table 1 shows the teaching competence of the preservice teachers when taken as a whole, was "very high" ( $\mathrm{M}=4.90, \mathrm{SD}=0.080)$. On Lesson Plan, the mean value of the pre-service teachers major General Education $(\mathrm{M}=4.99, \quad \mathrm{SD}=0.041)$ was higher than the mean value of the ECE $(M=4.93$, $\mathrm{SD}=0.131)$ and HELE (M=4.83, $\mathrm{SD}=0.314)$. On Presentation of the Lesson, the mean value of the pre-service teachers major ECE $(\mathrm{M}=4.93$, $\mathrm{SD}=0.131$ ) was higher than the mean value of Gen 
Ed $(M=4.82, S D=0.185)$ and HELE $(M=4.80$, $\mathrm{SD}=0.245)$. On the Classroom Management, the pre-service teachers major in ECE $(M=4.90$, $\mathrm{SD}=0.138$ ) has a higher mean value than the Gen ED $(\mathrm{M}=4.84, \mathrm{SD}=0.197)$ and HELE $(\mathrm{M}=4.72$, $\mathrm{SD}=0.191$ ). On Evaluation of Students Performance, the pre-service teachers major's in Gen Ed $(M=4.99, S D=0.0411)$ and ECE $(M=4.99$, $\mathrm{SD}=0.086)$ has the higher mean value than the HELE (M=4.96, SD=0.116). On Communication
Skills, the pre-service teachers major in HELE $(\mathrm{M}=4.81, \mathrm{SD}=0.402)$ has a higher mean value than the ECE $(M=4.79, \quad S D=0.410)$ and Gen $E d$ $(\mathrm{M}=4.70, \mathrm{SD}=0.463)$. And on Personal Attributes, the pre-service teachers majors in Gen $\mathrm{Ed}(\mathrm{M}=4.97$, $\mathrm{SD}=0.164)$ and HELE $(\mathrm{M}=4.97, \mathrm{SD}=0.090)$ than the mean value of $\operatorname{ECE}(\mathrm{M}=4.95, \mathrm{SD}=0.186)$ major.

\section{Table 2}

\section{Teaching Competence of the Pre-Service Teachers when grouped according Sex}

\begin{tabular}{llll}
\hline Variable & M & SD & Interpretation \\
A. As a Whole & 4.90 & 0.080 & Very High \\
B. Lesson Plan & & & \\
Male & 5.00 & 0.000 & Very High \\
Female & 4.92 & 0.199 & Very High \\
C. Presentation of the Lesson & & & \\
Male & 4.81 & 0.116 & Very High \\
Female & 4.86 & 0.199 & Very High \\
$\begin{array}{l}\text { D. Classroom Management } \\
\text { Male }\end{array}$ & 4.81 & 0.259 & Very High \\
Female & 4.83 & 0.184 & Very High \\
$\begin{array}{l}\text { E. Evaluation of Students Performance } \\
\text { Male }\end{array}$ & & & \\
Female & 5.00 & 0.000 & Very High \\
$\begin{array}{l}\text { F. Communication Skills } \\
\text { Male }\end{array}$ & 4.98 & 0.086 & Very High \\
Female & & & \\
G. Personal Attributes & 4.63 & 0.518 & Very High \\
Male & 4.78 & 0.420 & Very High \\
Female & & & \\
& 5.00 & 0.000 & Very High \\
\hline
\end{tabular}

Legend:

Scale Interpretation

4.21 to 5.00 - Very High

3.41 to $4.20-\quad$ High

2.61 to $3.40-\quad$ Average

1.81 to $2.60-\quad$ Low

1.00 to 1.80 - Very Low

Table 2 presents the teaching competence of the pre-service teachers when grouped according to sex. On Lesson Plan, the mean value of the male $(\mathrm{M}=5.00, \quad \mathrm{SD}=0.000)$ pre-service teacher was higher the female $(\mathrm{M}=4.92, \mathrm{SD}=0.199)$ pre-service teacher. On Classroom Management, the female $(\mathrm{M}=4.86, \mathrm{SD}=0.199)$ pre-service teacher has a higher mean value than the male $(M=4.81$, $\mathrm{SD}=0.116)$ pre-service teacher. On Evaluation of Students Performance, the male $(\mathrm{M}=5.00$, $\mathrm{SD}=0.000)$ pre-service teacher has a higher mean value than the female $(\mathrm{M}=4.98, \mathrm{SD}=0.086)$ preservice teacher. On Communication Skills, the female $(\mathrm{M}=4.78, \mathrm{SD}=0.420)$ pre-service teacher has a higher mean value than the male $(M=4.63$, $\mathrm{SD}=0.518$ ) pre-service teacher. Lastly on the
Personal Attributes, the male $(\mathrm{M}=5.00, \mathrm{SD}=0.000)$ pre-service teacher has the higher mean value than the female $(\mathrm{M}=4.96, \quad \mathrm{SD}=0.162)$ pre-service teacher.

Teachers are the key elements of maximizing the quality of education improving schools and successfully implementing curricula. In addition, teachers are the people who raise individuals that shape the future of a country. Therefore, there are qualities that teachers who have a role in the education and character development of children need. Every country has standards which specify the qualities that teachers should have and aims to equip pre-service teachers with these standards throughout their training. It is expected to be higher 
relationship amongst teacher competencies and attitudes because if individuals have knowledge, understanding and skills about teaching, they should have high attitudes about teaching profession. General competencies and attitudes are essential to enhance the quality of the teaching profession. This will only be possible if the competencies are known and they can be taught to pre and inservice teachers through education and training programs.

The finding in the present study that female preservice teachershave higher perceptions of professional competencies reveals that they feel better about possessing the "general knowledge, skills and attitudes "that exist in the definition of general teaching competencies. Similarly, female pre- service teachers were found to have a better attitude towards the teaching profession. In some studies about attitude in the teaching profession (Aşkar and Erden, 1987; Tanrı̈ğen, 1997; Oral, 2004; Üstün et al.,2004; Çakır, 2005; Çapriand Çelikkaleli, 2008) the results have been in favor of females, while in others (Sürücü, 1997; Çakır et al.,2006; Davran, 2006)in Koksa (2014) there have been results in favor of males. Even though an effective undergraduate program would be expected not to create a difference between the two genders, the Turkish assumption that "teaching is a woman's job" may have affected individuals' attitudes towards their profession. No meaningful difference was found in the general teaching competencies and attitudes towards the profession of pre-service teachers who graduated from teacher training high schools and others. Seferoğlu (2004) in Koksa (2014) examined the teaching competency levels and perceptions of pre-service teachers, and likewise found no difference as regards the type of high school. No difference between pre-service teachers who graduated from teacher training high schools and others has not been an expected finding. The former are institutions attended by students who decide to enter the teaching Profession at an early age, where they learn about the profession and instruction. No difference between the general competencies and professional attitudes of these Pre- service teachers and others reveals deficiencies with postelementary education guidance towards a profession and the curricula of teacher training high schools.

\section{Table 3}

\section{Mother Tongue Proficiency of the Pre-Service Teacher}

\begin{tabular}{lllll}
\hline Variable & N & M & SD & Interpretation \\
\hline A. As a Whole & 97 & 1.80 & 0.331 & Very Good \\
B. Sex & & & & \\
Male & 8 & 1.84 & 0.213 & Very Good \\
Female & 89 & 1.80 & 0.340 & Very Good \\
C. Major & & & & \\
Gen ED & 37 & 1.69 & 0.211 & Very Good \\
HELE & 26 & 2.13 & 0.408 & Good \\
ECE & 34 & 1.67 & 0.162 & Very Good \\
\hline
\end{tabular}

\section{Legend:}

Scale

$1.0-$

1.10 to $1.50-$

1.60 to $1.20-$

2.10 to $2.50-$

2.60 to $3.00-$

3.10 to $4.00-$

4.10 to $5.00-$

Excellent

Interpretation

Superior,

Very Good

Good

Fair/ Passing

Conditional Failure

Failure

Table 3 presents the mother tongue proficiency of the pre-service teacher, when taken as a whole $(\mathrm{M}=1.80, \quad \mathrm{SD}=0.331)$, the mother tongue proficiency of the pre-service teacher was "very good". Both male $(\mathrm{M}=1.84, \mathrm{SD}=0.213)$ and female $(\mathrm{M}=1.80, \mathrm{SD}=0.340)$ has a very good proficiency on mother tongue, however the mean value of the male participants was higher than the female participants. The pre-service teachers majoring Gen Ed $(\mathrm{M}=1.69, \quad \mathrm{SD}=0.211)$ and $\mathrm{ECE} \quad(\mathrm{M}=1.67$,
$\mathrm{SD}=0.162$ ) has a very good proficiency on mother tongue, while the pre-service teacher major HELE $(\mathrm{M}=2.13, \mathrm{SD}=0.408)$ has a good proficiency on mother tongue.

It is interesting to note that Home Economics and Livelihood Education got the lowest rating in proficiency compared to the other courses included here. If we consider the courses where Mother Tongue is easily accommodated HELE would be 
one of those since it covers the more common area of day to day life. Some factors may have played in this regard. One of which is the reality that English has always been the functional language in the Philippines. The participants of this study are not exempted.

The result of the study conducted by Mahboob and Cruz (2015) revealed that most respondents perceived English to be their strongest language with the biggest number, $64 \%$, considering themselves to be high proficient in English. In contrast, more respondents rated themselves as low proficient in Tagalog and / or in their non- Tagalog mother tongue. This is significant for MTBE because with more respondents being comfortable with English. A school system based on mother tongues as media of instruction will definitely met with resistance, particularly among the demographic represented in the survey. Moreover, the participants were also asked to identify which languages should be taught as subjects in school, majority of them pointed out that English should be taught as a subject in school, with barely $50 \%$ identifying the need to have Tagalog as a subject. Mother tongues as subjects barely got any support, with more respondents identifying the need to have other international languages as subjects rather than other local languages.

To support the importance of indigenous and vernacular languages, UNESCO in Gorio, Galino Et al (2014)1953 released a policy paper recommending that every pupil should begin formal education in his or her mother tongue. UNESCO has clearly supported initial reading, writing, and learning in the language of the learner on psychological and pedagogical grounds. This position has since been strengthened by abundant researches that students learn to read and write most efficiently and effectively when instruction takes place through the medium of their mother tongue (Dutcher, 1995)Gorio, Galino Et al (2014). In brief, there is overwhelming evidence that students learn to read more quickly when taught in their mother tongue; students who learn to read in their mother tongue also learn to read in a second or foreign language more quickly than those who initially are taught to read in a second language or foreign language, and students taught to read in their mother tongue acquire academic content and skills more quickly (Mehrotra, 1998)Gorio, Galino Et al (2014).

The use of mother tongue in education has ranged from psychological and pedagogical to human rights-based and to sociocultural context. This idea on the use of mother tongue leads to the multiple definitions of literacy such as literacy as not simply knows how to read and write a particular script but applying this knowledge for specific purposes in specific cultural contexts (Hull \& Fernandez, 1999)Gorio, Galino Et al (2014). Moreover, Hymes (1964), as mentioned by Spolsky (2010)Gorio, Galino Et al (2014), urged the study of language in context and inclusion of language in the study of cultures. He asserted that literacy should involve "ethnography of communication". The ethnography of communication is further defined that language can be learned in a cultural context.

\section{Table 4}

Comparing Mother Proficiency and Teaching Competence of Pre - Service Teacher

\begin{tabular}{|c|c|c|c|c|c|c|}
\hline & $\begin{array}{l}\text { Mother } \\
\text { Proficiency }\end{array}$ & Tongue & $\begin{array}{l}\text { Teaching } \\
\text { Competence }\end{array}$ & df & t-value & p-value \\
\hline Pair & $\begin{array}{l}1.80 \\
(0.331)\end{array}$ & & $\begin{array}{l}4.90 \\
(0.080)\end{array}$ & 96 & $-81.667 * *$ & 0.00 \\
\hline
\end{tabular}

Note: $\mathrm{p}<0.05$, there was a significant difference

Utilizing the paired-sample t-test, table 4 shows that there was a significant difference between the mother tongue proficiency and teaching competence $[\mathrm{t}(96)=-81.667, \mathrm{p}=0.00]$ of the preservice teachers at 0.05 level of significance.

\section{Table 5 \\ Relationship between Mother Proficiency and Teaching Competence}

\begin{tabular}{llll}
\hline Relationship & N & r-value & p-value \\
\hline $\begin{array}{l}\text { Teaching Competence } * \\
\text { Mother Tongue Proficiency }\end{array}$ & 97 & $-.440^{* *}$ & 0.00 \\
\hline
\end{tabular}

Note: $p<0.05$, there was a significant relationship

Table 5 presents that there was a negative relationship between mother proficiency and teaching competence $[\mathrm{r}(97)=-0.440, \mathrm{p}=0.00]$ at 0.05 level of significance. 


\section{Summary of Findings}

The following significant findings were drawn from the study:

1. The teaching competence of the pre-service teacher in terms of lesson plan, presentation of the lesson, classroom management, evaluation of student performance, communication skills and personal attributes when taken as a whole and grouped according to major was "Very High".

2. The teaching competence of the pre-service teacher in terms of lesson plan, presentation of the lesson, classroom management, evaluation of student performance, communication skills and personal attributes when taken as a whole and grouped according to sex was "Very High".

3. The Mother Tongue Proficiency of the preservice teacher when taken as a whole and grouped according to sex and major was "Very Good". However, when grouped according to courses taken HELE students got only "Good".

4. Significant difference exists between teaching competence and mother tongue proficiency.

5. Significant relationship exists between teaching competence and mother tongue proficiency.

\section{Conclusions}

In view of the findings of the study, the following conclusions are advanced:

1. The College of Education has provided the necessary competencies to the pre-service teachers which resulted a "very high" level of competence as rated by the critique teachers in their respective cooperating school.

2. The College has inculcated to the minds of the pre-service teachers the importance of Mother Tongue Based Education, thus they are doing their best to be proficient in this new challenge in the K-12 program by the Department of Education. However, there is a wide room for improvement towards excellence.

3. Teaching competence has impact on Mother Tongue Proficiency or the other way around.

\section{Recommendations}

Based on the foregoing findings and conclusions of the study, the following recommendations are formulated:

1. The College must continue giving the necessary competencies that the students in the College of Education may sustain the "Very High" level of competence during their preservice teaching.

2. The College must continue to intensify the teaching of EDMOTO (Mother Tongue Subject) to improve the level of proficiency of the pre- service teachers and target excellence.
A study may be conducted to determine the factors that resulted in the "Good" only proficiency rating of HELE students as compared to the "Very Good" rating of the students in other courses.

3. Faculty members handling EDMOTO subjects may be sent to seminar- workshop to enrich or enhance them regarding the recent implementation of Mother Tongue Based Education so that they can continually sustain the competencies that they give to the preservice teachers to improve the level of proficiency of these students.

4. The College must continue to consistently examine and supervise the pre-service teachers to sustain their "very high" level of teaching competence.

5. Other researchers may conduct a study to determine other related factors that resulted to high level of teaching competence and good level of proficiency in Mother Tongue.

\section{References}

1. Abu Sharbain, I. \& Tan, K. (2012) Pre-service Teachers' Level of Competence and their Attitudes towards the Teaching Profession. Retrieved February 13, 2017 from www.ajssh.leena-

luna.co.jp/AJSSHPDFs/Vol.1(3)/AJSSH2012( 1.3-02).pdf

2. Gorio, D., Galino, A.et. al (2014) Factors Affecting the Implementation of the Mother Tongue-Based Multilingual Education as Perceived by Teachers in Baguio and Benguet. Retrieved February 13, 2017 from sites.google.com/site/languageandmothertongu e/home/research-on-mtb-mle-implementation

3. Koksa N, (2014) Competencies in Teacher Education: Preservice Teachers' Perceptions about Competencies and their Attitudes. Retrieved February 13, 2017 from www.academicjournals.org/article/article1379 669756_Koksal.pdf

4. Mahboob, A \& Cruz, P (2015) English and Mother Tongue Based Multilingual

Education: Languages Attitudes in the Philippines. Retrieved February 13, 2017 from www.academia.edu/5182319/English_and_mo ther-tongue-

based_multilingual_education_Language_attit udes_in_the_Philippines

5. Theeb, R.S., et.al; (2013) A Professional Competencies among Pre-Service Teachers in Special Education from Their Perspectives. Retrieved February 13, 2017 from www.questia.com/library/journal/1G1386917900/profesional-competencies-amongpre-service-teachers. 